\title{
The Magnitude of Perceived Professionalism and Its Associated Factors Among Nurses in Public Referral Hospitals of West Amhara, Ethiopia
}

\author{
Hailemichael Kindie Abate' \\ Addisu Taye Abate' \\ Zewdu Baye Tezera' \\ Debrewok Tesgera Beshah ${ }^{2}$ \\ Chilot Desta Agegnehu (iD ${ }^{3}$ \\ Mohmmed Adem Getnet (ID) \\ Birhaneselassie Gebeyehu Yazew (ID)' \\ Mahlet Temesgen Alemu ${ }^{2}$ \\ Chilot Kassa Mekonenn (D) \\ Chanyalew Worku Kassahun' \\ 'Department of Medical Nursing, College \\ of Medicine and Health Sciences, \\ University of Gondar, Gondar, Ethiopia; \\ ${ }^{2}$ Department of Surgical Nursing, College \\ of Medicine and Health Sciences, \\ University of Gondar, Gondar, Ethiopia; \\ ${ }^{3}$ Community Nursing Unit, College of \\ Medicine and Health Sciences, University \\ of Gondar, Gondar, Ethiopia
}

Correspondence: Hailemichael Kindie Abate

Tel +251965321790

Email haile206k@gmail.com
Introduction: Nursing professionalism is how nurses view their work and is a guide for the behavior of nurses in practice to ensure patient safety and quality care. Poorly perceived nursing professionalism can lead to poor patient outcomes, which decrease the promotion and career options of nurses.

Objective: The aim of this study is to assess the perceived prevalence of nursing professionalism among nurses in Public Referral Hospitals of West Amhara Regional State, Ethiopia.

Methods: An institution-based cross-sectional study was conducted among 423 nurses from January to February 2021. A simple random sampling method was used to reach the study subject. A self-administered questionnaire was used for data collection. To explain the study variables, frequency tables and percentages were used. A binary and multiple logistic regressions were conducted to see the relation between the dependent variable and independent variables.

Results: A total of 407 nurses participated in the study with a response rate of $99.3 \%$. The overall prevalence of good perceived nursing professionalism was found to be $24.8 \%$. Variables such as having $>10$ years experience (adjusted odds ratio $(\mathrm{AOR})=1.2,95 \% \mathrm{CI}$ : 2.9-5.57) a day working shift ( $\mathrm{AOR}=2.36,95 \% \mathrm{CI}: 0.78-6.67)$, having professional identification $(\mathrm{AOR}=5.44,95 \% \mathrm{CI}: 4.38-8.45)$, and getting medical service $(\mathrm{AOR}=1.23,95 \% \mathrm{CI}$ : 1.11-2.28) were significantly associated with perceived good nursing professionalism.

Conclusion: The findings of this study showed that only one-fifth of nurses had perceived good nursing professionalism. In this study, variables such as nursing experience $>10$ years, working shift, having professional identification, and getting medical services were significantly associated with good perceived nursing professionalism. The policymakers ought to incorporate free medical services to enhance the attitude of nurses toward nursing professionalism.

Keywords: nursing, professionalism, hospital, Ethiopia

\section{Introduction}

Nursing professionalism reflects how nurses view their work (conceptualization of obligations, attributes, interactions, attitudes, and role behaviors required) and is a guide for the behaviors of nurses in practice to ensure patient safety and quality care. $^{1,2}$ A systematic review study conducted among 61 reviews around the globe showed that poorly perceived nursing professionalism can lead to poor patient outcomes in nursing care. ${ }^{3}$ A cross-sectional study conducted among 23,159 nurses across European countries stated that poorly perceived nursing professionalism 
leads to a $5-17 \%$ increase of intention to leave their career. ${ }^{4}$ Another cross-sectional study conducted in Saudi Arabian among 350 nurses showed that poorly perceived nursing professionalism leads to $76 \%$ of intention to leave their career. ${ }^{5}$ An explanatory descriptive cross-sectional study conducted in East Africa from 551 participants showed that one-third of the nurses had a negative image of the nursing profession and leads to a decrease in the promotion and career options. ${ }^{6}$

Nurses who value professionalism exhibited adherence to practice standards and technical competence. ${ }^{2}$ It is also important to have professional and value-based foundations around it. ${ }^{7}$ These values are important to healthcare facilities because they are an important way of living out ethical commitment and affect patient safety and outcomes. $^{8}$

Professionalism prominence in nursing is often influenced by both internal and external arguments. Historians, sociologists, and nurses themselves struggle to determine whether professionalism is present or absent in nursing care. ${ }^{9}$ In the past three decades, there was a lack of expansion in roles and autonomy in a variety of nurses working ininpatient and outpatient settings. Nurse professionalism has become more significant than ever and has a great demand in health care settings. ${ }^{10,11}$

Professionalism in nursing can be changed by modifying the working environment of nurses, increasing the social and professional expectations of nurses for the next generation, changing faculty institutional responsiveness, and strengthening in-service education. ${ }^{12}$ The low level of nursing professionalism leads to negative outcomes such as increased turnover and decreased productivity of nurses in the work setting. Furthermore, poor nursing professionalism can decrease the trustful relationship between the profession and the public, which influences the professional status as a reputable profession. ${ }^{13}$

A cross-sectional descriptive study conducted in the US among 221 nurses showed that nursing professionalism was associated with the current position in nursing, current employment status, place of education, years of experience, and duration of nursing association. ${ }^{14}$ To our knowledge, there has been limited research done in Ethiopia as well as no study conducted in the current study area. Therefore, this study aimed to assess the perceived professionalism of nurses and its associated factors. The result of this finding would be used as supporting information to the Ethiopia Nursing Association (ENA) and the Federal Ministry of Health (FMOH) to set policies and guidelines for nursing professionalism.

\section{Methods}

\section{Study Settings and Period}

This study was conducted at five public referral hospitals in the Northwest Amhara Regional State, Ethiopia from January to February 2021. The regional state has a population of 28 million (mid-2018), 14 zones, three city administrations, and 180 sub-city administrations (139 rural and 41 urban). ${ }^{15}$ It also has 80 hospitals ( 8 referrals, 2 general, and 73 primary hospitals), 847 health centers, and 3342 health posts. ${ }^{16}$ Despite the increased number of health facilities, shortages of skilled health personnel, medical equipment, drugs, and medical supplies, inefficient and inequitable use of health resources are the challenges of the region. ${ }^{17}$

\section{Study Design and Population}

An institutional-based cross-sectional study was conducted among nurses working in the public referral of the West Amhara region. All nurses who worked at the five referral hospitals' were the source population, whereas all nurses who were in the selected health institutions and available during the study period were the study population.

\section{Inclusion and Exclusion Criteria}

All nurses who were working in the five referral hospitals and available during the data collection period were included in this study, whereas those nurses who were seriously ill during the data collection period were excluded from this study.

\section{Sample Size, Sampling Technique, and Procedures}

The sample size of this study was estimated by using the single population proportion formula $\mathrm{n}=\left(\mathrm{Z} \frac{\alpha}{2}\right) 2 * \mathrm{p}(1-\mathrm{p}) /(\mathrm{d}) 2$. In the formula " $\mathrm{n}$ " denotes the sample size, " $\frac{\alpha}{2}$ " is the reliability coefficient of standard error at the $5 \%$ level of significance with $z=1.96$, "p" is the proportion and " $\mathrm{d}$ " is the level of standard error. Then 423 sample sizes were estimated after adding 10\% of the nonresponse rate for the study participants. Currently, there are five referral hospitals in West Amhara regional state from which samples were selected. For each hospital, the total sample size was allocated proportionally based on 
the number of nurses they have. Then, systematic random sampling was used to select patients from each hospital.

\section{Study Variables \\ Dependent Variables}

Perceived nursing professionalism:

Good: participants who scored between 80 and 100\% (92-115 points) of the total sum of the perceived nursing professionalism scores. ${ }^{18}$

Moderate: participants who scored 60-79\% (69-91 points) of the total sum of perceived nursing professionalism scores. ${ }^{18}$

Poor: participants who scored less than 60\% $(<69$ points) of the total sum of perceived nursing professionalism scores. $^{18}$

\section{Independent Variables}

Sociodemographic variables (age, work experience, work unit, nurse-patient ratio, lack of vision, lack of focus from the Ministry of Health).

Nurse-patient ratio: the standard by which how many patients each nurse is responsible for during the shift. ${ }^{19}$

Focus of Ministry of Health: focus the individual nurse on the ministry of health rules and regulations. ${ }^{20}$

Organizational variables (availability of life insurance, community view of nursing professionals, membership in a professional organization, and salary).

Life insurance: the medical services given by the nurse within the working health institution. ${ }^{21}$

Prospective views of the nursing profession: the better future view of the nurses toward the nursing profession. ${ }^{2}$

Membership to the community: any members of health associations in the community such as the Ethiopian Nursing Association, to ease any collaborative work. ${ }^{22}$

\section{Data Collection Tools, Measurements, and Procedures}

The tool incorporates two parts, the sociodemographic related factors and the question that assesses the perceived professionalism. Perceived nursing professionalism was assessed by a questionnaire of the nurse

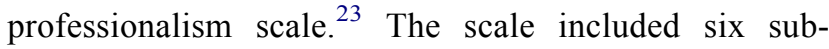
scales and multiple items: improving quality of care (four items), maintaining professional competence (three items), fulfilling professional responsibilities (four items), interprofessional collaboration (seven items), professional behaviors (three items), and value for the patient (two items). The questions are answered on a 5-point Likert scale (1=strongly disagree, 2=disagree, $3=$ neutral, 4=agree, and 5=strongly agree). Each Likert scale was assigned with points (strongly disagree $=1$ point, disagree $=2$ points, neutral $=3$ points, agree $=4$ points, and strongly agree $=5$ points). The overall level of perceived nursing professionalism was assessed based on Bloom's cutoff point. This cut-point is widely accepted and applied to operationalize the outcome variables of studies conducted on the knowledge, practice, and perception/attitude aspects of the study participants. Based on this cutoff point, the score between 80 and 100\% (92-115 points) from the total 23 items questions with a 5-point Likert scale was good perceived nursing professionalism, 60-79\% (69-91 points) moderate perceived nursing professionalism and less than $60 \%$ (<69 points) was scored as poor perceived nursing professionalism. ${ }^{18}$ The reliability of the tool for nursing professionalism was assured with the Cronbach's alpha of 0.76 . The content validity of the data collection tool was assured and checked by inviting experts in the field and their recommended modification has been done. Data were collected using a structured self-administered questionnaire from each participant at selected referral hospitals in the Northwest Amhara region of Ethiopia. The data collection was facilitated by five trained professional nurses assigned to each selected hospital. Upon data collection, the data collectors instructed the participants to complete the questionnaire independently to maintain transmitting of information between the participants.

\section{Data Quality Assurance}

Before collecting the data, the face and content validity of the data collection tool was assured and checked by inviting experts in the field. The data collectors and supervisors were trained about the study purpose and protocol. The research data collection tool was pretested to check the fitness of the tool for the study settings and necessary correction was made. The investigators exchanged all necessary information regarding the data collection procedures with the supervisors daily. Furthermore, the respondents had been given a brief orientation before the interview. In addition, detailed feedback was provided to the data collectors. The collected data were coded per the operational definition of the study variables. The data were checked and rechecked by the principal investigators for its completeness. 


\section{Data Management and Analysis}

EPI- DATA version 3.1 was used for data entry and STATA version 14 statistical software was used for data analysis. The collected data were checked for completeness and accuracy before analysis. Descriptive statistics was made using statistical measurements. Frequencies, percentages, means, and standard deviations were used as a statistical measurement. Finally, tables and graphs were used to report findings. The binary and multivariable logistic regression analysis was conducted to identify associated factors. Model fitness was checked by using the Hosmer-Lemeshow goodness of fit test $(p=0.65)$ and interpreted as a model fitted. All variables fulfilled the chisquared assumption and checked its odds ratio. Multicollinearity of the continuous variable was checked using variance inflation factor (VIF) and its values lie between 1 and 10, which is interpreted as no multicollinearity. Bivariable and multivariate logistic regression analyses were used to identify associated factors. Those variables with a $p$-value less than 0.2 in the bivariable analysis were entered into the multivariable analysis. The backward selection process was used to see the final associated variables. Those variables with a $p$-value less than 0.05 with a $95 \%$ confidence interval were considered as significantly associated with outcome variables.

\section{Ethical Considerations}

The study was performed based on the ethical standards put down under the declaration of Helsinki. Ethical clearance was obtained from the institutional ethical review committee of the School of Nursing and College of Health Science of University Gondar with an ethical clearance letter reference number of December 15, 2020 RNo: V/P/RCS/05/SAS/2020. Supportive letters were obtained from Amhara Regional state health bureau and then their copies were delivered to each hospital. After understanding the purpose of the study, written informed consent was obtained from the study participants. Confidentiality of participants' information was kept.

\section{Results}

\section{Sociodemographic Characteristics of} Patients

A total of 407 nurses participated in this study with a response rate of $96.2 \%$. The mean age of the participants was 31.28 with a standard deviation (SD) of 5.29 years. The higher proportion of the study participants, 196
(48.2\%) were from the University of Gondar Comprehensive Referral Hospital. More than half, 212 (52.1\%) were male participants and 265 (65.1\%) were married. The majority of the participants, 360 (88.5\%), were degree holders and 373 (91.6\%) were staff nurses in their working unit. More than half of the participants, 58.7\%, and 63.6\% had 3501-8000 ETB (Ethiopian birr) (US \$76.5-171.9) monthly salary and gave service for more than six patients per day respectively. Almost half of the participants, $202(49.6 \%)$ had nursing experience $\leq 5$ years. About 295 (72.5\%) participants were working in the day shift, and $232(57 \%)$ were working eight hours or less per day. Among the total participants, 218 (53.6\%) had no membership in the professional organization, and 274 (67.3\%) responded that the Ministry of Health had no focus on the nursing profession. About $77.6 \%$ and $55 \%$ had no satisfaction with salary and no availability of life insurance for nurses, respectively (Table 1).

\section{Perceived Prevalence of Professionalism}

The mean score of the participants was $83.23 \pm 16.37$ and the areas with low mean scores were in the areas of value for the patient (7.32 \pm 1.71$)$, maintaining professional competence (10.8 \pm 2.11$)$, and professional behavior (11.04 $\pm 2.19)$. The highest mean score was in the area of interprofessional collaboration $(26.11 \pm 4.49)$ (Table 2).

The overall prevalence of good perceived professionalism was $24.8 \%$ with $95 \%$ CI: $20.6-29.0$, whereas poor perceived professionalism was $9.3 \%$ with $95 \%$ CI: $6.6-$ 12.3 (Table 3).

\section{Factors Associated with Perceived Professionalism}

In the multivariable regression analysis, four variables such as experience in years, working shift, having professional identification, and getting medical service were significantly associated with good perceived nursing professionalism. In this regard, having higher nursing experience ( $>10$ years) was 1.2 times $(\mathrm{AOR}=1.2,95 \% \mathrm{CI}$ : 2.9-5.57), the odds of good perceived professionalism than compared with the experience of $\leq 5$ years. The odds of good perceived professionalism was 2.36 times $(\mathrm{AOR}=2.36,95 \% \mathrm{CI}$ : 0.78-6.67) more in day shift working nurses than night shift working nurses. Having professional identification was 5.44 times $(\mathrm{AOR}=5.44,95 \% \mathrm{CI}$ : 4.38-8.45) good perceived professionalism than which had no professional identification. The odds of good perceived 
Table I The Sociodemographic Characteristics Nurses Working Public Referral Hospitals of West Amhara Regional State, Ethiopia $2021(N=407)$

\begin{tabular}{|c|c|c|c|}
\hline Variable & Category & Frequency $(n)$ & Percent (\%) \\
\hline \multirow[t]{5}{*}{ Working hospital } & University of Gondar & 196 & 48.2 \\
\hline & Tibebe Ghion & 60 & 14.7 \\
\hline & Felege Hiwot RH & 50 & 12.3 \\
\hline & Debre Tabor RH & 53 & 13.0 \\
\hline & Debre Markos RH & 48 & 11.8 \\
\hline \multirow[t]{2}{*}{ Sex } & Female & 195 & 47.9 \\
\hline & Male & 212 & 52.1 \\
\hline \multirow[t]{4}{*}{ Age group } & $20-29$ & 174 & 42.8 \\
\hline & $30-39$ & 205 & 50.4 \\
\hline & $\geq 40$ & 28 & 6.9 \\
\hline & Mean/SD of age & 31.28 Mean & SD \pm 5.29 \\
\hline \multirow[t]{2}{*}{ Marital status } & Single & 142 & 34.9 \\
\hline & Married & 265 & 65.1 \\
\hline \multirow[t]{3}{*}{ Education status } & Diploma & 17 & 4.2 \\
\hline & Degree & 360 & 88.5 \\
\hline & MSc and above & 30 & 7.4 \\
\hline \multirow[t]{2}{*}{ Position at work } & Head & 32 & 7.9 \\
\hline & Staff & 375 & 92.1 \\
\hline \multirow[t]{3}{*}{ Experience in years } & $\leq 5$ & 202 & 49.6 \\
\hline & $6-10$ & 168 & 41.3 \\
\hline & $>10$ & 37 & 9.1 \\
\hline \multirow[t]{4}{*}{ Salary/month ETB (US \$) } & $3000-3500(\$ 65.51-\$ 76.4)$ & 60 & 14.7 \\
\hline & $350 I-8000(\$ 76.5-\$ 17 I .9)$ & 239 & 58.7 \\
\hline & $800 \mathrm{I}-10,500(\$ 170-\$ 229.3)$ & 97 & 23.8 \\
\hline & $>10,500(>\$ 229.3)$ & 11 & 2.7 \\
\hline \multirow[t]{2}{*}{ Patient-nurse ratio } & $\leq 6$ & 148 & 36.4 \\
\hline & $>6$ & 259 & 63.6 \\
\hline \multirow[t]{2}{*}{ Working shift } & Day & 232 & 57.0 \\
\hline & Night & 175 & 43.0 \\
\hline \multirow[t]{2}{*}{ Hours worked/day } & $\leq 8$ & 209 & 51.4 \\
\hline & $>8$ & 198 & 48.6 \\
\hline \multirow[t]{2}{*}{ Membership of the professional organization } & Yes & 189 & 46.4 \\
\hline & No & 218 & 53.6 \\
\hline \multirow[t]{2}{*}{ Flexibility schedule } & Yes & 284 & 69.8 \\
\hline & No & 123 & 30.2 \\
\hline \multirow[t]{2}{*}{ Having professional identification } & Yes & 290 & 71.3 \\
\hline & No & 117 & 28.7 \\
\hline \multirow[t]{2}{*}{ Satisfaction with salary } & Yes & 91 & 22.4 \\
\hline & No & 316 & 77.6 \\
\hline \multirow[t]{2}{*}{ Prospective vision to the profession } & Yes & 258 & 63.4 \\
\hline & No & 149 & 36.6 \\
\hline
\end{tabular}


Table I (Continued).

\begin{tabular}{|l|l|l|l|}
\hline Variable & Category & Frequency (n) & Percent (\%) \\
\hline Focus of Ministry of Health to the nursing profession & Yes & 133 & 32.7 \\
& No & 274 & 67.3 \\
\hline Availability of life insurance for nurses & Yes & 183 & 45.0 \\
& No & 224 & 55.0 \\
\hline
\end{tabular}

Abbreviations: ETB, Ethiopian birr; RH, referral hospital; SD, standard deviation.

professionalism was 1.23 times $(\mathrm{AOR}=1.23,95 \% \mathrm{CI}$ : $1.11-$ 2.28) more in getting medical service compared to those who did not get the medical services (Table 4).

\section{Discussion}

The current study was focused on the perceived prevalence of professionalism and its contributing factors of nurses in the public referral hospitals of northwest Ethiopia. The overall prevalence of good perceived nursing professionalism was $24.8 \%$ with $95 \% \mathrm{CI}$ : 20.6-29.0. This finding was supported by the cross-sectional studies conducted among 210 and 518 nurses in Ethiopia, ${ }^{2,12}$ respectively. The possible justification might be due to the positive perception of study participants towards nursing professionalism as a result of the presence of good role models in the profession. This idea was supported by the cross-sectional studies conducted among 350 nurses in Saudi Arabia and 352 nurses in Turkey. ${ }^{5,24}$ This finding was lower than a crosssectional multilevel study conducted among 5920 nurses and physicians across European countries, which ranges from $71-95 \%,{ }^{25}$ a survey conducted among 1501 nurses in Japan $(58.8 \%){ }^{10}$ and a cross-sectional descriptive study conducted among 221 in the USA (89.9 mean score). ${ }^{14}$ The possible reason might be that the study participants in this study were only nursing professionals, whereas the

Table 2 The Subscale of Nursing Professionalism Among Nurses Working Public Referral Hospitals of West Amhara Regional State, Ethiopia 2021 ( $N=407)$

\begin{tabular}{|l|l|}
\hline Subscale of Perceived Professionalism & Mean $\mathbf{E S D}$ \\
\hline Improving quality of care & $13.22 \pm 3.26$ \\
Maintaining professional competence & $10.8 \pm 2.1 \mathrm{I}$ \\
Fulfilling professional responsibilities & $14.74 \pm 2.6 \mathrm{I}$ \\
Interprofessional collaboration & $26.11 \pm 4.49$ \\
Professional behaviors & $11.04 \pm 2.19$ \\
Value for the patient & $7.32 \pm 1.7 \mathrm{I}$ \\
Total score & $83.23 \pm 16.37$ \\
\hline
\end{tabular}

Abbreviation: SD, standard deviation. participants in the study done across European countries were among physicians and nurses. This composite effect might make a difference in the magnitude of the perceived nursing professionalism. Furthermore, the low development of professional behavior and excessive workload, long working hours, and inadequate services provided in the nursing profession might be the reason to have low perceived professionalism in developed countries such as Ethiopia. ${ }^{26,27}$

In the multivariable regression analysis, four variables such as nursing experience in years, working in a day shift, having professional identification, and getting medical service were significantly associated with good perceived nursing professionalism. In this regard, having ( $>10$ years) nursing experience was 1.2 times the odds of good perceived nursing professionalism compared to the experience of $\leq 5$ years. This finding was in line with a crosssectional descriptive study conducted among 221 nurses in the USA. ${ }^{14}$ The possible justification might be the higher experience can lead to expertise in nursing staff and become a role model for other nurses which increases the nursing perceived professionalism. This explanation was supported by a descriptive cross-sectional study conducted among 380 nurses in Saudi Arabia. ${ }^{28}$ The odds of good perceived nursing professionalism was 2.36 times more in day shift working nurses than night working shift. This finding was supported by a cross-sectional study conducted among 72 nurses in Iran. ${ }^{29}$ The possible

Table 3 The Level of Perceived Nursing Professionalism Among Nurses Working Public Referral Hospitals of West Amhara Regional State, Ethiopia 202I ( $N=407)$

\begin{tabular}{|l|l|l|l|}
\hline $\begin{array}{l}\text { Level Perceived Nursing } \\
\text { Professionalism }\end{array}$ & $\mathbf{N}$ & Percentage & $\mathbf{9 5 \%} \mathbf{C l}$ \\
\hline Good & 101 & 24.8 & $20.6-29.0$ \\
Moderate & 268 & 65.8 & $60.9-70.5$ \\
Poor & 38 & 9.3 & $6.6-12.3$ \\
\hline
\end{tabular}

Abbreviation: $\mathrm{Cl}$, confidence interval. 


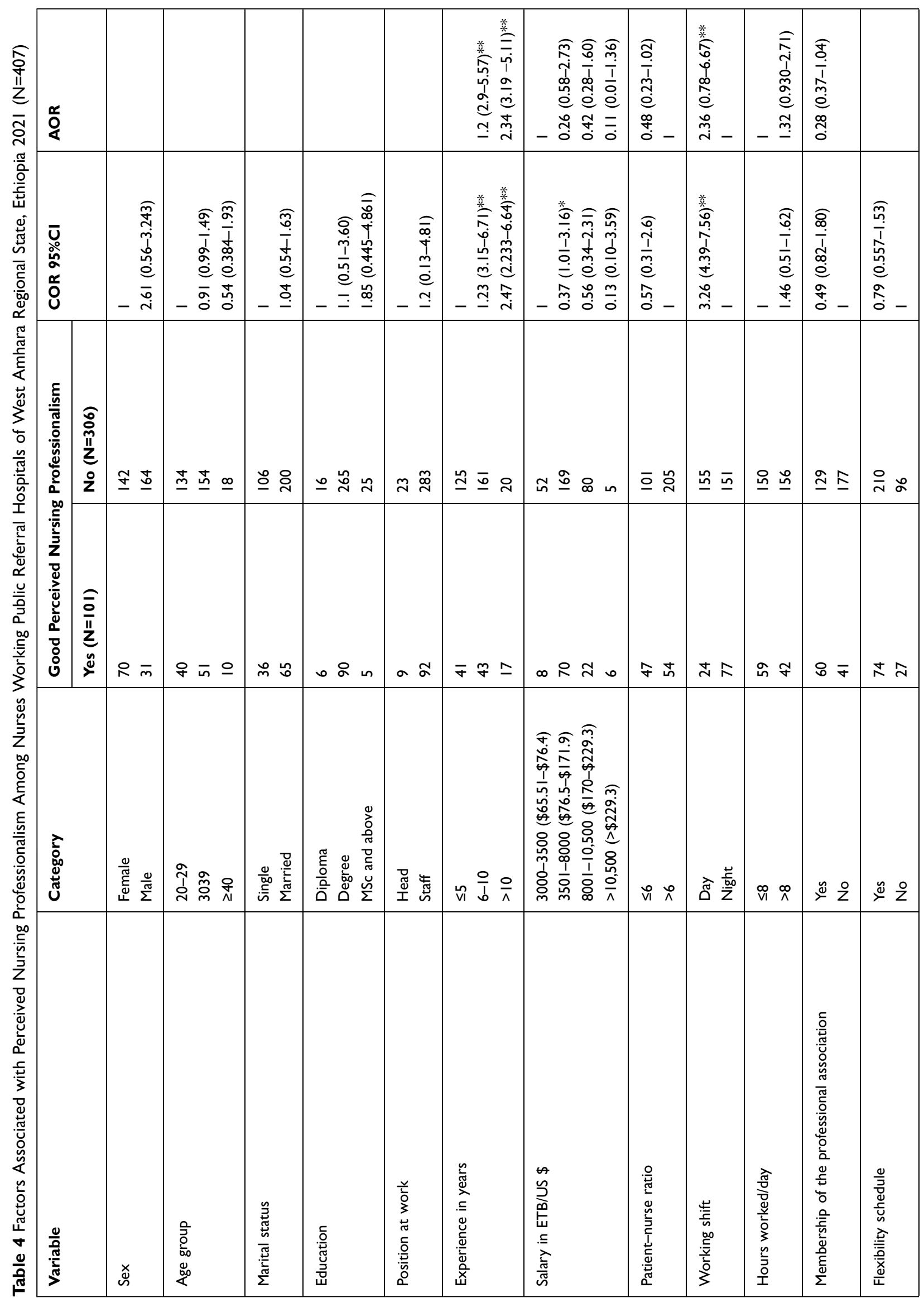




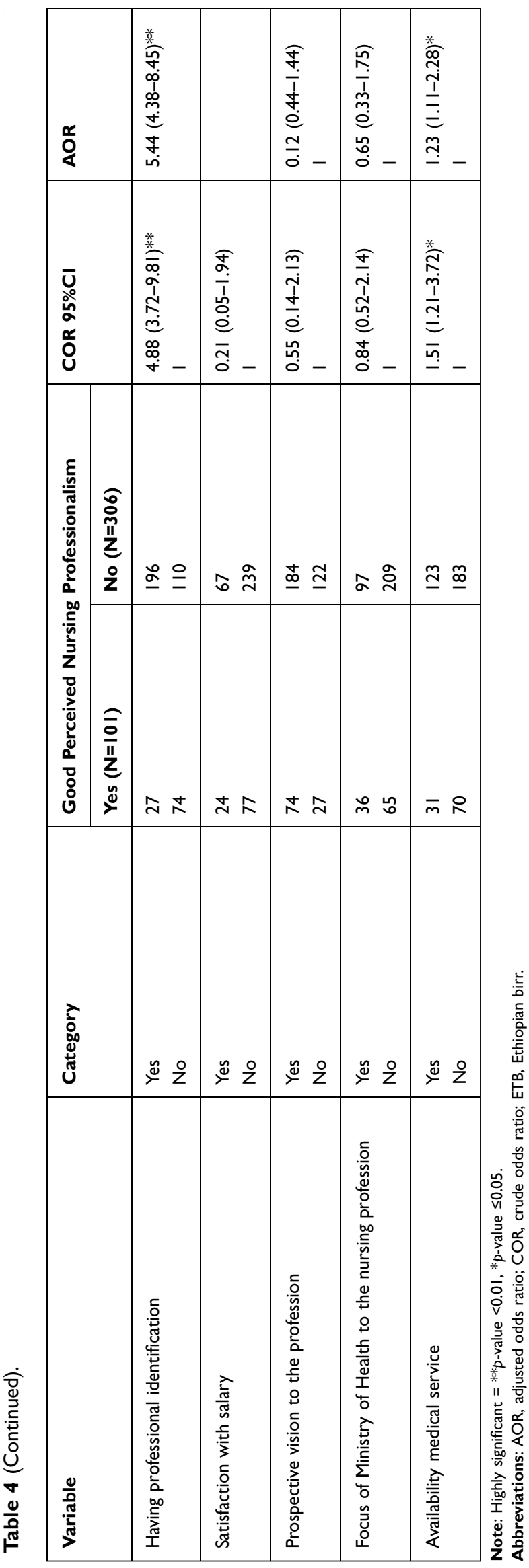

reason might be because of the negative effect of the night-shift working on health, such as sleeplessness and other welfare issues, which lead to poorly perceived nursing professionalism. This explanation was supported by a systematic review conducted among 26 reviews across the globe. ${ }^{30}$ Having professional identification was 5.44 times the odds of good perceived nursing professionalism compared to those who did not have such professional identification. This finding was supported by a quasiexperimental study conducted among 63 nurses in the USA. $^{31}$ The possible reason might be because having professional identification can increase the value given by the profession and increase the perceived nursing professionalism of the nurses. ${ }^{32}$ The odds of good perceived nursing professionalism was nearly 1.23 times more in getting medical services compared to those who did not get the medical services. This finding was supported by a qualitative explanatory study conducted among 18 professional nurses in South Africa. ${ }^{33}$ The possible justification might be because of getting free medical services in a health-care setting can enhance the attitude of nurses in their profession. This reason was supported by a crosssectional study conducted among 462 nurses in India. ${ }^{34}$

\section{Strength and Limitations of the Study}

The invitation of experts to assess the validity of the questionnaire is the strength of this study. The cross-sectional nature of the study cannot rule out the cause-effect relationship. Furthermore, longitudinal research might be needed to explore how to continue increasing the level of nursing professionalism.

\section{Conclusion}

The findings of this study showed that only one-fifth of nurses had good perceived nursing professionalism. In this study, variables such as nursing experience $>10$ years, working in a day shift, having professional identification, and getting medical services were significantly associated with greater perceived nursing professionalism. The policymakers ought to incorporate free medical services to enhance the attitude of nurses towards nursing professionalism. Providing professional identification and maintaining professional competence and professional behavior will increase perceived nursing professionalism. 


\section{Abbreviations}

AOR, adjusted odds ratio; COR, crude odds ratio; ENA, Ethiopian Nursing Association; ETB, Ethiopia birr; SD, standard deviation; STATA, statistics and data; VIF, variance inflation factor.

\section{Data and Material Availability}

The raw data is available from the corresponding authors on rational request and the summary data is available in the main document.

\section{Acknowledgment}

Our deepest gratitude goes to the University of Gondar for all expenses of this research work and study participants who participated in the research. The authors also would like to give great appreciation to the data collectors and supervisors for their contribution to this paper.

\section{Author Contributions}

All authors made a significant contribution to the work reported, whether that is in the conception, study design, execution, acquisition of data, analysis, and interpretation, or in all these areas; took part in drafting, revising, or critically reviewing the article; gave final approval of the version to be published; have agreed on the journal to which the article has been submitted; and agree to be accountable for all aspects of the work.

\section{Funding}

The study was supported by the University of Gondar College of medicine and health science. The funding does not have a further role in the design, data collection, analysis, drafting, and preparation of the manuscript for publication.

\section{Disclosure}

The authors report no conflicts of interest in this work.

\section{References}

1. Dikmen Y, Karataş H, Arslan GG, Ak B. The level of professionalism of nurses working in a hospital in Turkey. J Caring Sci. 2016;5(2):95. doi: $10.15171 /$ jcs. 2016.010

2. Fantahun A, Demessie A, Gebrekirstos K, Zemene A, Yetayeh G. A cross sectional study on factors influencing professionalism in nursing among nurses in Mekelle Public Hospitals, North Ethiopia, 2012. BMC Nurs. 2014;13(1):1-7. doi:10.1186/1472-6955-13-10

3. Coster S, Watkins M, Norman IJ. What is the impact of professional nursing on patients' outcomes globally? An overview of research evidence. Int $J$ Nurs Stud. 2018;78:76-83. doi:10.1016/j. ijnurstu.2017.10.009
4. Heinen MM, van Achterberg T, Schwendimann R, et al. Nurses' intention to leave their profession: a cross sectional observational study in 10 European countries. Int J Nurs Stud. 2013;50(2):174184. doi:10.1016/j.ijnurstu.2012.09.019

5. Aljedaani SM. Nurses' perceptions of nursing as a profession and its impact on their intention to leave their career: staff nurses in Jeddah City. J Nurs Health Sci. 2017;6(3):13-23.

6. Ndirangu EW, Sarki AM, Mbekenga C, Edwards G. Professional image of nursing and midwifery in East Africa: an exploratory analysis. BMC Nurs. 2021;20(1):1-11. doi:10.1186/s12912-02000531-w

7. Fatemi NL, Moonaghi HK, Heydari A. Exploration of nurses' perception about professionalism in home care nursing in Iran: a qualitative study. Electron Physician. 2018;10(5):6803. doi:10.19082/6803

8. Julie H, Bimray P, Jooste K. Professionalism experiences of undergraduate learner nurses during their 4-year training programme at a Higher Education Institution in the Western Cape, South Africa. Curationis. 2019;42(1):1-8.

9. Makeda KAN. The degree of professionalism among actively practicing registered nurses in south Texas: TUI University; 2010

10. Tanaka M, Yonemitsu Y, Kawamoto R. Nursing professionalism: a national survey of professionalism among $\mathrm{J}$ apanese nurses. Int $J$ Nurs Pract. 2014;20(6):579-587. doi:10.1111/ijn.12201

11. Miller BK. A model for professionalism in nursing. Today's or Nurse. 1988;10(9):18-23.

12. Solomon Y, Belachew T, Beker J. Professionalism and its predictors among nurses working in Jimma Zone Public Hospitals, South West Ethiopia. Med Edu. 2015. doi:10.1111/medu.12818

13. Cruess RL, Cruess SR, Johnston SE. Professionalism: an ideal to be sustained. Lancet. 2000;356(9224):156-159. doi:10.1016/S01406736(00)02458-2

14. Kim-Godwin YS, Baek HC, Wynd CA. Factors influencing professionalism in nursing among Korean American registered nurses. J Prof Nurs. 2010;26(4):242-249. doi:10.1016/j.profnurs. 2009.12.007

15. Kiros M, Dessie E, Jbaily A, et al. The burden of household out-ofpocket health expenditures in Ethiopia: estimates from a nationally representative survey (2015-16). Health Policy Plan. 2020;35 (8):1003-1010. doi:10.1093/heapol/czaa044

16. Kloos. AA. Evaluation of the 2007 Ethiopian census data, with an emphasis of coverage in the Amhara Region. Ethiop $J$ Dev Res. 2014;36(number 1):45.

17. Ethiopia Health Sector Financing Reform/Health Finance and Governance Project. HSFR/HFG end of project regional report Amhara; 2018

18. Kaliyaperumal K. Guideline for conducting a knowledge, attitude and practice (KAP) study. AECS Illumination. 2004;4(1):7-9.

19. Sharma SK, Rani R. Nurse-to-patient ratio and nurse staffing norms for hospitals in India: a critical analysis of national benchmarks. $J$ Family Med Primary Care. 2020;9(6):2631. doi:10.4103/jfmpc. jfmpc 24820

20. Habte T, Tsige Y, Cherie A. Survey on the quality of care standards in a nursing/midwifery training hospital at tikur anbessa specialized hospital in Addis Ababa, Ethiopia, 2019. Adv Med Edu Pract. 2020;11:763. doi:10.2147/AMEP.S260339

21. Zemene A, Kebede A, Atnafu A, Gebremedhin T. Acceptance of the proposed social health insurance among government-owned company employees in Northwest Ethiopia: implications for starting social health insurance implementation. Arch Public Health. 2020;78(1):110. doi:10.1186/s13690-020-00488-x

22. Cline D, Curtin K, Johnston PA. Professional organization membership: the benefits of increasing nursing participation. Clin J Oncol Nurs. 2019;23(5):543-546. doi:10.1188/19.CJON.543-546

23. De Braganca AV, Nirmala R. Nurse professionalism scale: development and psychometric evaluation; 2020. doi: 10.21203/rs.3.rs$21673 / \mathrm{v} 1$ 
24. Elibol E, Seren AKH. Reasons nursing students choose the nursing profession and their nursing image perceptions: a survey study. Nurs Pract Today. 2017;4(2):67-78.

25. Lombarts KM, Plochg T, Thompson CA, Arah OA, Consortium DP. Measuring professionalism in medicine and nursing: results of a European survey. PLoS One. 2014;9(5):e97069. doi:10.1371/journal. pone.0097069

26. Price S, Reichert C. The importance of continuing professional development to career satisfaction and patient care: meeting the needs of novice to mid-to late-career nurses throughout their career span. Administrative Sci. 2017;7(2):17. doi:10.3390/admsci7020017

27. Rizany I, Hariyati RTS, Handayani H. Factors that affect the development of nurses' competencies: a systematic review. Enferm Clin. 2018;28:154-157. doi:10.1016/S1130-8621(18)30057-3

28. Fernández-Feito A, Palmeiro-Longo M, Hoyuelos SB, García-Díaz V. How work setting and job experience affect professional nurses' values. Nurs Ethics. 2019;26(1):134-147.

29. Yarmohammadi H, Pourmohammadi A, Sohrabi Y, et al. Work shift and its effect on nurses' health and welfare. Soc Sci. 2016;11(9):2337-2341.

30. Gunn V, Muntaner C, Villeneuve M, Chung H, Gea-Sanchez M. Nursing professionalization and welfare state policies: a critical review of structural factors influencing the development of nursing and the nursing workforce. Nurs Inq. 2019;26(1):e12263. doi:10.1111/nin. 12263
31. Sabanciogullari S, Dogan S. Effects of the professional identity development programme on the professional identity, job satisfaction and burnout levels of nurses: a pilot study. Int J Nurs Pract. 2015;21 (6):847-857. doi:10.1111/ijn. 12330

32. Traynor M, Buus N. Professional identity in nursing: UK students' explanations for poor standards of care. Soc Sci Med. 2016;166:186194. doi:10.1016/j.socscimed.2016.08.024

33. Molokomme V, Seekoe E, Goon D. The perception of professional nurses about the introduction of the National Health Insurance (NHI) in a Private Hospital in Gauteng, South Africa. Open Public Health J. 2018;11(1):234-242. doi:10.2174/1874944501811 010234

34. Singh T, Kaur M, Verma M, Kumar R. Job satisfaction among health care providers: a cross-sectional study in public health facilities of Punjab, India. J Family Med Primary Care. 2019;8(10):3268. doi:10.4103/jfmpc.jfmpc_600_19

\section{Publish your work in this journal}

Nursing: Research and Reviews is an international, peer-reviewed, open access journal publishing original research, reports, reviews and commentaries on all aspects of nursing and patient care. These include patient education and counseling, ethics, management and organizational issues, diagnostics and prescribing, health outcomes, economics and resource management, improving patient safety in all settings. The manuscript management system is completely online and includes a very quick and fair peer-review system. Visit http://www. dovepress.com/testimonials.php to read real quotes from published authors. 